\title{
Homeowners as Engaged Participants:
}

\section{Determining information needs to maximize the environmental benefit of green renovations}

\author{
Mahtab Sabet \\ Department of Computer Science \\ University of Toronto \\ Toronto, Canada \\ mahtab@cs.toronto.edu
}

\author{
Steve Easterbrook \\ Department of Computer Science \\ University of Toronto \\ Toronto, Canada \\ sme@cs.toronto.edu
}

\begin{abstract}
Green home renovation is a socio-technical process involving homeowners and professionals. Homeowners undertaking a green renovation encounter unfamiliar terms and must navigate potentially conflicting information from different sources. These challenges prevent some homeowners from being fully engaged in the renovation process, which can lead to less than optimal homeowner satisfaction and failure to use green features to their greatest extent. This paper details the information requirements of homeowners, drawing on seven interviews that were conducted with those who have done a green home renovation. We put forward suggestions that can be used to improve the green home design process, contributing to higher uptake, more satisfied homeowners, and more environmentally friendly use of renovated homes. We also conclude that there is a need for homeowners to be contributors to the knowledge base surrounding green renovations. Finally, we propose a model for an ICT platform to satisfy the needs identified in our research.
\end{abstract}

Index Terms - Green, home, renovation, requirements, information

\section{INTRODUCTION}

The UN Environmental Program estimates that buildings contribute roughly one third of all global greenhouse gas emissions, primarily through the consumption of energy during their operational lifetimes [1]. As the lifetime of existing building stock extends for decades to centuries, reducing the energy consumption of existing buildings is a vital strategy for tackling climate change.

In the ICT sector, a common response to this challenge is to develop technologies for the 'smart' home, using the potential of home automation and network-enabled devices to optimize energy consumption. In government policy analysis, the focus tends to be on finding the appropriate financial incentives to persuade homeowners to improve insulation, switch to high efficiency heating and lighting systems, and install micro-scale renewable energy generation, such as solar panels.

But few people ask what homeowners themselves need. Currently, very few homeowners engage in renovation aimed at making their homes greener, or even include environmental considerations when undertaking renovations for other reasons. We argue that engaged homeowners are an essential element in encouraging broader uptake of green renovations, and that techniques adapted from requirements engineering and partici- patory design, harnessed in an ICT platform, offer a significant potential to achieve this engagement [2].

This paper reports the results of an initial study of the motivations of and barriers faced by homeowners who choose to undertake green renovation, which is a renovation process aimed at transforming the home into a building that is environmentally sustainable throughout its remaining lifecycle. Green building generally requires considering energy efficiency, water conservation, waste and pollution reduction, and responsible materials [3]. Our research questions are focused on eliciting homeowners' requirements for green home renovation, especially their information needs:

1) What motivates homeowners to choose green home renovation projects?

2) What criteria do homeowners use in their decisionmaking, both in the choice of which professionals to work with and in the design choices they make for their homes?

3) What information do homeowners currently use during the planning and implementation of green home renovations, and where do they get it from?

4) What information needs are currently unmet?

We conducted seven semi-structured interviews with homeowners who have completed a green renovation. We wanted to know if homeowners were getting the information they need to do a renovation that fits with their values. We discovered that as important as it is for homeowners to have meaningful access to the right information, it is also important for them to be generating knowledge, contributing to the knowledge base surrounding green renovations. Based on our findings, we propose a model for an ICT platform that can help engage homeowners by giving them greater access to reliable information and providing a means for them to contribute to the knowledge base.

\section{RELATED WORK}

In his paper, Jakob [4] explains the importance of understanding the legal and economic drivers promoting or preventing green renovations. Governments that understand these drivers can design policies that will encourage sustainable renovations. Jakob's analysis revealed that high upfront costs are a barrier to green renovations. Maller, Horne, and Dalton [5] also discuss how financial incentives encourage individuals to make sustainable renovation choices. 
Connolly and Prothero [6] discuss how an individual's sense of personal responsibility for environmental problems contributes to feelings of empowerment, leading to the desire to undergo a green renovation. However, individuals can be uncertain about specific renovation choices, particularly if they are unfamiliar with the technical aspects involved in home renovations.

Berry [7] makes a connection between building design and requirements engineering, and describes the similarities between house and software requirements engineering, including "the importance of the client understanding the plans/ specifications in validating that the plans/specifications capture his/her intent", and "the usefulness of a model/prototype in the client's understanding of the plans/specification."

Homeowner engagement in the green renovation process is important. Weeks et al. [8] describe 8 stages of increasing homeowner engagement, and present a set of ICT tools to help move them through the stages. Their subsequent paper [9] focuses on specific measures to move homeowners from the stage of evaluating expert advice to making home improvements. Massung et al. [10] reach similar conclusions to Weeks et al. on the obstacles that prospective green renovators need to overcome, and present a smartphone application focused on open-home events to mitigate some of these barriers.

Carroll and Rosson [11] identify two propositions involved in participatory design. The first, a moral proposition, states that "users have a right to be directly included in the process of design." The second, pragmatic, proposition states that "directly including the users' input will increase the chances of a successful design outcome." These design ideas are radical in that they "challenge commonly-held beliefs about the role of a designer as a professional" [12], especially in an industry like building design that has well-defined and rigid roles for professionals.

The green renovation design process would benefit from these "radical" participatory design ideas. Presenting information to homeowners in a manner calculated to engage them in the design process will improve enthusiasm for and uptake of green buildings. By learning how to effectively engage homeowners in the process, we can increase the environmental benefit of green renovations, the satisfaction of homeowners, and enthusiasm for future green building projects.

\section{Methodology}

To understand the information needs of homeowners, we focused on those who have recently completed green renovations. The lead author reached out to a green renovation company in Toronto, Canada, to provide access to recent customers. Seven interviews were conducted with a total of ten people. Six of these interviews were with former clients of this green renovation company, and one interview was with someone who had done their own renovation.

Participants were asked questions about their home and the renovation process. An interview guide with a series of questions was used to start a conversation, but the interview itself was open-ended. Questions asked covered reasons for choosing the renovation company, how important sustainability is to them, information sources available before and during the renovation, how much feedback they were invited to give, the perceived "green-ness" of each renovation decision, and return on investment. The interviews were recorded and transcribed for analysis. Interviewees checked the transcripts for accuracy.

Interview transcripts were coded via an open iterative coding strategy inspired by grounded theory techniques. As the codes emerged we looked for common patterns and themes. The concepts presented in this paper emerged from the data; they were not pre-supposed by the authors.

\section{SUSTAINABILITY}

Homeowners can have a diversity of priorities or values when planning sustainable renovations, and understanding these will clarify homeowners' information needs. This section will detail the values interviewed homeowners identified as important.

All interviewees stated that sustainability was important to them, and that they wanted to work with professionals who felt strongly about completing a renovation sustainably:

The vision of the business attracts customers, and [professional] seemed to have a good vision. (Interview 4)

I felt very comfortable... with [renovation company] from the beginning, and we in fact shared their values when it came to environmental things. So I think that those are the things that really made us choose them. (Interview 6)

For all interviewees, sustainability included energy efficiency. For certain homeowners it also included waste diversion, sourcing local materials, and use of non-toxic materials.

\section{1) Waste Diversion}

All interviewees mentioned their appreciation of their renovation company's policy on waste diversion and reusing materials. One homeowner noted that a previous contractor she had worked with insisted they demolish the house to build a bigger house in its place, as it would be cheaper than renovating:

...we don't need a bigger house...That's just more space than we need, and it's going to consume more energy. And I hate the idea of throwing out stuff that's perfectly good into the waste just because it's cheaper... (Interview 3)

Many homeowners appreciated that their renovation company deliberately sifted through the rubble created by the renovation to reuse as much as possible (by selling copper pipes, using scrap pieces of wood for framing, donating old fixtures, etc.). One homeowner even made his flooring choice based on a company's reuse policy:

...I picked a company...who makes a cork floor, because they have a program saying whenever you're done, just let us know and we'll unclick your floor and we'll give it to habitat for humanity. So that's great, this gets another life. (Interview 2) 
A few interviewees lamented the increasing trend towards a "throwaway society", explaining that for them, sustainability involves investing in quality materials, and not throwing away items that are still functional.

\section{2) Sourcing Local Materials}

Interviewees wanted to use local materials, to contribute to their local economy and reduce the carbon footprint associated with transporting materials over long distances.

The sourcing of that product - how was it made, where was it made, how far is it coming. Those are all a factor because they all bring up your carbon output. We tried to get local as much as we could. (Interview 7)

...this is really local stuff. It's made here in Canada. What other things do you buy in life that have such local impact? (Interview 4)

...ultimately we chose a sustainable wood product from Quebec. That was the other thing [renovation company] talked about, getting stuff that was made here rather than having to import it from either the United States or very far away. (Interview 6)

\section{3) Healthy Materials}

Every interviewee mentioned using healthy or non-toxic materials in the building. For many interviewees, this practice was an integral part of sustainable building. One interviewee was adamant about not bringing "nasty chemicals" into her home. A number of interviewees had a specific preference for using sealants, glues, and paints that are not off-gassing. Healthy materials were also linked in at least one homeowner's mind with return on investment: she believed that the health features in her home could be attractive to potential buyers.

I think the health features we have in this home will make it a big selling point. I think those are easy to sell...Our home has no allergens, no toxic chemicals; we've never used a toxic chemical to clean... This is a very healthy home, and I think that's easy to project to a buyer... (Interview 5)

\section{DESIRED OUTCOMES}

This section will detail the desired renovation outcomes as stated by interviewees. In general, homeowners were interested in comfort, affordability, and return on investment.

\section{A. Comfort}

Improved home comfort and aesthetics is one of the main desired outcomes in a renovation, and factors into homeowners' decisions. Every interviewee identified comfort as important to them, many noting that their home was more comfortable after renovating. One couple noted that their home before the renovation had very little insulation, and after insulating:

...it's a much, much cozier house. In the middle of winter if it's a sunny day the sun's coming in through our nice big south-facing window, you don't have to have the furnace on. It's cozy, it's warm. (Interview 3)
Another interviewee noticed that her home had become more comfortable because of the consistent temperature:

...we can go anywhere in the house and it's the same temperature. There's no, the basement's freezing and the upstairs back wall is cold. (Interview 4)

For some, comfort was a factor when deciding on materials. Some interviewees decided on cork floors over other options based on comfort.

\section{B. Affordability}

Home renovations can be expensive, and finding affordable options is important to many homeowners. Every interviewee mentioned affordability as a factor in their decision-making process. Interviewees believed that the general public has the impression that green homes are necessarily more expensive. While this impression was not shared the interviewed homeowners, many of them forewent certain green features that they wanted to incorporate into their ideal home, because they did not fit the budget. Examples include alternative forms of insulation, such as straw-bale construction or denim, and environmentally friendly energy/heat sources, such as solar panels or geothermal.

Many interviewees mentioned that they used professionals' guidance to help them save money. Professionals can present options to homeowners, describe advantages and disadvantages, and estimate costs. One couple described their appreciation for this professional guidance. They had access to tiles at-cost, and wanted to use them for their kitchen floor. However, their renovation company convinced them to go with cork floor, because although the material cost would be higher, the labour-intensive process for installing tile would result in a much higher overall cost. In some cases where the homeowners had done their own research and found a material, their contractor was able to provide an alternative that fit their needs better and was more affordable; this required the contractor to be aware of the homeowners' goals and requirements.

A few of the interviewees took advantage of the ecoEnergy program, a (now discontinued) government program providing grants to retrofit homes to be more energy-efficient. For some homeowners, the fact that they would be getting some money back from the government helped justify the cost of renovation activities. However, as one interviewee noted, it is not just the dollar value of the rebate that makes a difference:

I think it's just the fact that the government is encouraging this, it sort of legitimizes that direction. Because a rebate usually has some advertising with it, it's just more in the public eye, that maybe I should be doing this to my house. And then whether you actually apply for the [rebate] or not, it may influence your design decisions. (Interview 4)

\section{Return on Investment}

Return on investment (ROI) was not something that renovation companies discussed with the interviewees. The main predictor of how important ROI was to a homeowner was the 
length of time they believed they would stay in the house. For those who saw themselves staying in the home for the rest of their lives, ROI at time of sale was a non-factor:

It wasn't a major driving force for why we did the renovation, saving money...because we knew we were going to live here for quite a long time...There were a couple of times when [the architects] were trying to advise us on things for resale value and we were like no, it's not a factor. (Interview 3)

...we decided we would stay here for the rest of our lives. If you've got someone who knows they're going to move in 10 years, then the incentive to do a good job is very low. So then your return on investment becomes enormous, that's a huge part of the decision-making. (Interview 4)

Conversely, for those who did not plan on staying in their home long-term, ROI was a decisive factor in determining the scale of the renovation:

...we're not long-term purchasers...I would have done more, but I wouldn't have done a deep energy retrofit, simply because this isn't our home forever...we would have never recouped the ROI. (Interview 5)

Aside from looking to a future sale of the home, some homeowners were concerned about the ongoing usage cost of green features, and how long it might take them to get an ROI on the given feature:

I was looking at the payback period [of a given feature], and I was also looking at the upfront cost...It became a combination of how much benefit something would provide in that 10-year span - ideally 5-year, actually...So, I remember when I looked at geothermal, it would take me a very long time to pay that back. (Interview 2)

Another homeowner expected that, in her real estate market, the value of her house would increase regardless of renovation activities, making ROI considerations less important.

Thus, while comfort and affordability were key concerns for all homeowners, ROI's relevance to decision making varied depending on both the homeowners' planned residence and beliefs about market trends and the inherent value-increase in a renovated home.

Comfort, affordability, and ROI were considered separately at certain points of the interviews, but it became apparent that these factors are also tightly linked for homeowners, whose decision-making process involves trade-offs between the three. For one interviewee, comfort was as or more important than ROI:

...I have a green roof that was just purely something I wanted to do, and enjoy. Or like the drainage on the property. There's no payback for that kind of stuff, but it's com- fort. And we enjoy the garden upstairs, and it has an aesthetic value. It's more about that warm fuzzy feeling than anything else. (Interview 2)

Some homeowners sacrificed features that could increase ROI for comfort, a decision often correlated to the length of intended stay in the home:

There were a couple of times where [the architects] were like "You should really keep a bathtub in your bathroom for resale value." And I was like "Well, we're going to be here for the next 50 years and we'd much rather have a nice large walk-in shower...So, no, get rid of the tub, it's just going to crowd the bathroom." (Interview 3)

\section{Environmental Role Models}

Some interviewees attached importance to serving as a role model to friends, family, and neighbours.

I realized that I needed to start with myself - I couldn't step up on a soapbox and say everyone needs to be doing something about it when I wasn't. So I started this blog and I didn't want it to be accusatory or anything like that - I wanted it to be attractive. So it is very light-hearted and hopefully I inspire my friends and my family and anybody else who is reading my blog to take action as well. (Interview 1)

For interviewees who saw themselves as role models (and who would be classified as "validators" on the scale presented by Weeks et al. [8]), this self-perception was an integral part of their broader commitment to environmental responsibility; they felt it important that their home not only serve them, but also demonstrate to others that going green need not be expensive or unrealistic. Many interviewees framed their own green renovation project in the context of changes that need to occur in society.

With climate change, I believe people have to do what they can to reduce the greenhouse gas impact... if you can afford to do it and reduce greenhouse gas impact, that would be the first choice. You can't let your finances outrun your ideals, but the finances you do spend should be spent in a way that improves the planet, if it also meets your aesthetic objectives. (Interview 4)

\section{INFORMATION SOURCES}

We now turn to the sources of information currently available to homeowners, how homeowners felt about these sources, and what could be improved in presenting information to homeowners.

Homeowners are generally not trained in building science, construction methods, energy analysis, etc. How information is presented to these homeowners will determine how comfortable they are in getting involved in the renovation process.

Currently the information available to homeowners is derived from many sources, and is not always accessible. Some 
interviewees expressed frustration with the complexity of the information:

So overall I'm happy about what we were able to achieve, but sometimes you think you need an engineering degree if you really want to read and understand the information. (Interview 7)

One interviewee found it difficult to compare items he had researched:

I'd say the hardest stuff was finding comparative information, because the problem with a lot of the products is they aren't apples to apples. (Interview 2)

Another interviewee felt that there was not enough reliable information from authoritative sources:

It's like all information - there's too much of it, and there's not enough clarity on how to know if something is written by professionals or by hysterical people. (Interview 5)

Most respondents noted that through the renovation process, they had become significantly more knowledgeable about renovations, materials, and building science. Many spent several hours doing their own research, developing expertise in certain areas. One interviewee even made a career out of healthy sealants after her own renovation, because she had gained so much expertise.

...it became necessary for me to sign up for things like the professional subscriptions...because there's a lot of hysteria and bullshit out there, but I was able to sift through it. It took me so long that I actually made a career of it. That's how much effort it was. I got myself certified as a sustainable building advisor because there is a lot of information out there, and a lot of it is questionable...And so much conflicting advice... [I] t takes time and experience to put it all together and realize how all the different pieces interact with one another, and how that can make a really big difference. And there's very little out there that actually does that. (Interview 5)

\section{A. Professionals}

Professionals have expertise and can provide guidance to homeowners on home design, materials, and cost saving. If homeowners and professionals have a good working relationship, there is mutual trust and effective communication. This section will focus on professionals as an information source, and how the advice provided could be improved.

\section{1) Guidance}

Professionals can give guidance on materials choice, cost saving, how to analyze how "green" a product really is, and how the house works as a system.

a) Affordability

Professionals can advise homeowners on how to save money. Homeowners rely on professionals to have a broad knowledge of different available products, including affordable alternatives:

...I think it's great if you can get a contractor in there who is educated enough, and could go 'Actually, you could do this, and it'll actually save you money', or 'It's not that more expensive.' So you can have someone in there who can actually educate people. (Interview 1)

Sometimes renovation projects go over budget. When unexpected expenses prevent homeowners from completing the renovations as planned, professionals can help prioritize and replan:

When we had to scale back...[renovation company] would give us feedback when we told them what we wanted, and they would say 'This will be more expensive,' or 'That will be less expensive, '... they were very conscious of our budget and were constantly showing us where we were on it... (Interview 6)

\section{b) Greenwashing}

"Greenwashing" is a term used in sustainability discourse to describe a product or practice that is marketed as environmentally friendly, but whose positive environmental effects are, at best, negligible [13]. Homeowners are frequent targets of such marketing campaigns; without expertise they can have difficulty determining just how "green" a product is. A knowledgeable professional can help guide homeowners to truly green choices.

...there's so many products that say they're green, and even this first company we worked with, they would say things that were completely ridiculous, the amount of soy protein that's in your spray foam insulation is a green feature...there's certainly a lot of stuff out there that claims to be green, but just isn't at all. So unless you have experience with the products, it's not obvious right away sometimes. So that's where [renovation company] can make those kinds of materials decisions, but I think if you were doing it yourself that would be harder. (Interview 3)

...there's a lot of other things out there. And some of them you don't even know if it's greenwash. That's another reason we hired [professional], I'll ask "Is this just greenwash, or does this really mean anything?" (Interview 7)

\section{c) House as a System}

Most professionals understand that the house is a system, consisting of complex interactions of different components. It can be difficult to predict how a change in one part of the system can affect the house as a whole. For some homeowners this can be daunting:

Some of the passive heating and cooling stuff, we couldn't get our heads around how it was all going to work together as a system. (Interview 3) 
Many homeowners gained this understanding through the renovation process:

...we began working with the architect. At the time I didn't know about the integrated design process, which now I promote...until you start to see the whole house holistically, you just look for elements, like you think "I need a furnace,"...But now I know after 6 years of researching and studying, had we done a little more about the envelope, I might have even been able to have a smaller more efficient furnace, and used that extra savings for something else. So those are the things you learn over time. I would say the information you find out there - very little of it takes a big picture approach. (Interview 5)

This homeowner found herself getting bogged down in the huge amount of information available on small components of the system, when it would have been more helpful for her to learn how the house works as a system. Professionals can help provide homeowners with a holistic view of their home, and make recommendations that look at the big picture.

\section{2) Communication}

Good communication between homeowners and professionals is one of the most important factors in determining the success of a renovation.

[Renovation company] really were very good communicators. In-person, and by email. And you could even see the charts they had up every day that showed who was working on what, and where certain things were at. And that was a real change from previous contractors, where it was hard to get an answer. (Interview 3)

Homeowners found that frequent communication online was important:

Every day they had 2 or 3 photos of what happened that day... They would have regular updates and relate it to the budget that they started with. That weekly information is important to not have the project get out of hand. That you still are making decisions based on sound financial information... (Interview 4)

In some instances a breakdown of communication between professionals can cause issues, and the conflicting views of different experts can be confusing to homeowners:

...the problem is the engineer does everything theoretically but has no practical experience. And you give it to someone who actually builds something and they're like "What? That's just not feasible...it's going to cost a billion dollars and hours and labour, and it's really not necessary." (Interview 4)

3) Trust

Homeowners' trust of professionals is based on a few factors. Most interviewees said they felt comfortable with the pro- fessionals they worked with because of their knowledge base, treatment of employees, and billing method.

...the way they bill too is nicer, they bill by the day, by the hour. So there's no driving force for them to cut corners to make the job go faster. They work slower and get everything done right...it felt transparent about what they were doing, we weren't worried they were deliberately prolonging things to make more money. We could really get a feeling everyday of what they've been working on. (Interview 3)

While homeowners want to work with knowledgeable professionals, they also want someone who can admit when they don't know the answer to something:

...once they proved to be open to admitting what they didn't know, then I felt comfortable taking their recommendations pretty much at face value. And what I appreciated most in any of the supply chain was when people said "I'm not sure about that," and I would go and research and figure it out and then come back and then we would have that conversation together. (Interview 5)

Trust in professionals is not limited to the professionals onsite during the renovation. One homeowner described his interactions with manufacturers while doing research into materials:

...it didn't feel like there was enough third-party verification on all that information. I just kind of had to take companies' words for it. (Interview 2)

\section{B. The Internet}

Homeowners often have to do their own research in the renovation process. Many interviewees used blogs to learn about other peoples' experiences with their renovations.

Just a lot of blogs of other people that had done this. That was the major source, I'd say. There are a lot of people who had written about how they had done their green renovation, and stuff they found important...the Internet is amazing, so you can always find someone that's used [a certain product] before and try to find out... what their experience was. (Interview 3 )

A few homeowners used manufacturers' websites to get product information, but it was not clear how reliable the information was, as there is no third-party verification.

One interviewee noted that it was difficult to find sustainable products, and suggested that a database of green products or services would be very helpful for people looking to do green renovations.

\section{DISCUSSION}

As pointed out by Weeks et al. [8], in order to fully engage homeowners in the design process, we need to think about their information requirements. This section will explain how those 
requirements can be met, and the specific role ICT can play in meeting them more efficiently and effectively.

The interviews demonstrated that unbiased, reliable information, including from people who have already gone through green renovations, needs to be made accessible for homeowners without any experience in building science. Homeowners should also have access to knowledgeable professionals who share their sustainability values. These conclusions about homeowners' information requirements were not unexpected. What was noteworthy was the need for homeowners to contribute to knowledge as well.

Sustainability-minded homeowners want to feel that they are having a positive impact as environmental role models for friends, family and neighbours; but they can also feel they have an impact by contributing to a knowledge base. Several homeowners who responded to the call for participants for this study expressed that they were eager to share their experiences in hopes that they could contribute to green research. Some of them also write blogs about their renovation experiences. These homeowners would be classified as "validators" on Weeks et al.'s [8] scale of engagement, those who have completed a green building project and "must be given a platform to display their accomplishments to other householders." At least one homeowner, who became an expert on healthy sealants (Interview 5), would be classified as a "master" on this scale.

Many interviewees saw themselves as part of the renovation team, communicating with professionals and doing research on materials and products. In a few cases where homeowners chose to work with a material that the renovation company had not used before, they felt they contributed to the renovation company's knowledge base.

There is room in this relationship for continuous and mutual learning. Homeowners learn about green renovation from professionals, and professionals learn from their experiences working on different homes. By the same logic that informs information exchange during the renovation process, if homeowners and professionals keep in touch after the renovation, homeowners can continue to inform professionals about the use and performance of green features in their home, further contributing to expanding the knowledge base around green renovations. Engaging homeowners in the design process not only benefits their project, but future projects as well, either through the homeowner sharing their experiences with others, or through the renovation company learning and adapting. The company can play a role in plugging homeowners into a community in which they can contribute as validators.

ICT has the potential to make a great impact on green renovation by contributing to the development of an informationsharing community. One model that could meet most of the information needs that emerged in this study - both homeowners' need to receive information before and during their own project, and their need to share information as validators and masters - would be an application or website specifically for green renovations, on which homeowners and professionals can contribute, pooling their experience with materials, processes, systems, etc. The idea of using an app to contribute to retrofitting has been advanced by Massung et al. [10] in the context of open home events; this could be an important part of the proposed platform, which would also help capture and share the information described above. While a detailed elaboration of such a platform is beyond the scope of this paper, a few specific contributions to homeowner values and information requirements can be pinpointed:

1. The platform could help address the problem of "authoritative" information. Product reviews would be linked to the profiles of the contractor, homeowner, etc., allowing the user to understand the perspective from which the product is being assessed, and decide whether this person's appraisal is relevant. The review of a homeowner who is a "master" on Weeks et al.'s [8] scale, for instance, could more easily be distinguished from an uninformed review than is possible using diffuse sources on the internet, where anonymous reviews may have little value. Linking reviews to profiles, which could include detailed descriptions of homes, would also allow users to see how the product performed in a particular home context. In this way, the platform could provide a reliable, comprehensive database of green products and services, which one of our interviewees identified as a need.

2. Contractors and homeowners could use the site to advertise materials and fixtures that are removed from a home during renovation, allowing others in their region to obtain them. This would greatly enhance homeowners' ability to satisfy the values of waste diversion and sourcing local materials, as well as helping with affordability. Whereas currently, a homeowner hoping to obtain already-used materials for their home, or hoping to divert some of the waste generated during their renovation, may have difficulty locating a party at the other end of the transaction, this application would make this much more simple. This simplicity would make more contractors open to the idea of waste diversion as well, creating a greater pool of diverted material in a virtuous cycle.

3. The platform could be used to mobilize the green home community, for instance in support of government policy (such as the (re)implementation of programs like ecoEnergy). The governments' legislative support of green retrofitting not only eases the financial burden on homeowners taking this step, but creates a signal about societal priorities that can motivate homeowners. Given the reality of how lobbies and interest groups disproportionately impact the legislative process, the platform's potential to mobilize and organize a community in support of this kind of legislation could be of great value.

4. Direct professional advice will remain crucial, since each home and every homeowner's goals are unique. However, similarly to the diagnostic tool proposed by Weeks et al. as a means to engage homeowners at the "Evaluating Expert Advice" stage [8], the platform could help homeowners understand what questions to 
ask the professional, what factors need to be taken into consideration, and what alternative ways of dealing with a particular issue have been used by other homeowners.

5. As more contractors, including those not currently green-focused, come to see this platform as a useful way to reach potential clients, they will through using it be exposed to a greater body of knowledge about green building, helping steer more construction companies in this direction.

\section{CONCLUSION}

When homeowners are engaged in the green renovation process, the results are beneficial to the homeowners, the professionals they work with, and other homeowners contemplating a future green renovation. Homeowner engagement depends on having access to reliable information presented in a way that allows them to complete a renovation that aligns with their sustainability values. They need to work with professionals who share their values, and they need to feel as if they are also contributing to a knowledge base that will help others. An ICT platform along the lines discussed in this paper may be a valuable contribution to the green building movement.

\section{ACKNOWLEDGMENT}

We would like to thank Greening Homes for their assistance in finding interview participants, and the CANARIE project Green 2.0 for partial funding.

\section{REFERENCES}

[1] Buildings and Climate Change: Summary for Decision-Makers, 1st ed. United Nations Environment Programme, 2009, p. 4.

[2] C. Becker, S. Betz, R. Chitchyan, L. Duboc, S.M. Easterbrook, B. Penzenstadler, N. Seyff, C.C. Venters, S.A. and Kocak, "Requirements: The key to sustainability" in IEEE Software, pp.1, 2015.
[3] U.S. Environmental Protection Agency (2016, February 20). Definition of Green Building [online]. Available: https://archive.epa.gov/greenbuilding/web/html/about.html

[4] M. Jakob, "The drivers of and barriers to energy efficiency in renovation decisions of single-family home-owners." CEPE, 2007.

[5] C. Maller, R. Horne and T. Dalton, "Green Renovations: Intersections of Daily Routines, Housing Aspirations and Narratives of Environmental Sustainability," in Housing, Theory and Society, vol. 29, no. 3, pp. 255- 275, 2012.

[6] J. Connolly and A. Prothero, "Green Consumption: Life-politics, risk and contradictions", Journal of Consumer Culture, vol. 8, no. 1, pp. 117-145, 2008.

[7] D. Berry, "Software and House Requirements Engineering: Lessons Learned in Combating Requirements Creep", Requirements Engineering, vol. 3, no. 3-4, pp. 242-244, 1998.

[8] C. Weeks, C. Delalonde, and C. Preist, "Power law of engagement," in $2^{\text {nd }}$ International Conference on ICT for Sustainability, 2014.

[9] C. Weeks, C. Delalonde, and C. Preist, "Investigation into the slow adoption of retrofitting," in $29^{\text {th }}$ International Conference on Informatics for Environmental Protection, 2015.

[10] E. Massung, D. Schien, and C. Preist, "Beyond Behaviour Change," in $2^{\text {nd }}$ International Conference on ICT for Sustainability, 2014.

[11] J. Carroll and M. Rosson, "Participatory design in community informatics”, Design Studies, vol. 28, no. 3, pp. 243-261, 2007.

[12] M. Sabet and S. Easterbrook, "Engaging End Users in Green Building Design Software," in Proceedings of the Fourth International Workshop on Requirements Engineering for Sustainable Systems, Ottawa, Canada, August 24, 2015, CEURWS.org, online http://ceur-ws.org/Vol-1416/Session1Paper2.pdf

[13] K. B. Sheehan, "The Many Shades of Greenwashing: Using Consumer Input for Policy Decisions Regarding Green Advertisements" in Communicating Sustainability for the Green Economy. New York: M.E. Sharpe, 2014, ch. 3, pp. 43. 